\title{
Data Quality for Emergency Department BI Dashboard
}

\author{
Andy Koronios Jing Gao \\ University of South Australia, Australia \\ Email: andy.koronios@unisa.edu.au; jing.gao@unisa.edu.au
}

\begin{abstract}
As a powerful BI tool, dashboard is currently on the decision-makers' top concern lists. Many studies have been conducted on how to develop dashboard in the hospital environment, especially in the emergency departments (ED) where the doctors need precise, real time information of their patients in order to provide better services and shorten the waiting time. This study tries to discuss the actual data quality issues with the operation-level and middle-level managers emerged during the ED BI dashboard development projects. By conduct data quality issues and business processes mapping, issues are summarized under the well-known TOP model, thus providing guidance on types of data that need to be collected and required quality dimensions for reliable decision-making.
\end{abstract}

Keywords: Dashboard, Information Quality, Health Service and Emergency Department

\section{Introduction}

In Australia, the public health system is managed by the Department of Health or a similar government organization within each state. At the Department of Health (DoH) level, managers rely on data to report, manage and lead. Gendron and D'Onofrio (2001)'s [5] in the healthcare industry point out that the business contribution of leadership and management activities depends on the quality of the decisions that are made and, concomitantly, the quality of the data used to make them. Within the areas of public health services, emergency department (ED) performance is considered as a key performance benchmark, which often draws public attention.

Researchers (Bazarian and Schneider 1996, Lewandrowski 2004, Holland et al 2005) looked into the process improvement in ED on issues such as how to reduce the patient length of stay [2][7][8]. As a result, many researchers point out that providing quality data / information through Business Intelligence tools such as dashboards (as shown below) are of significant value to improve ED performance.

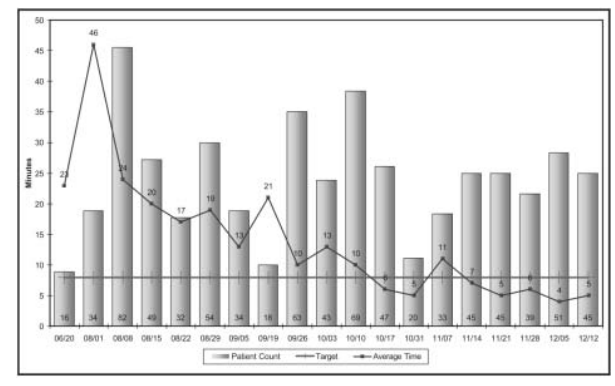

Fig. 1: Example of a simple ED dashboard.

As an important dimension for a successful BI dashboard, McKee (2001) asserts that data availability and data quality are critical issues for the health 
systems performance measures [10]. It must be noted that a number of studies have investigated the data quality indicators in the ED such as [6][9]. By bringing the data quality studies into BI, this study tries to adopt a processoriented approach to understand how data quality issues emerged through the ED data collection processes in order to provide guidance in ED BI projects.

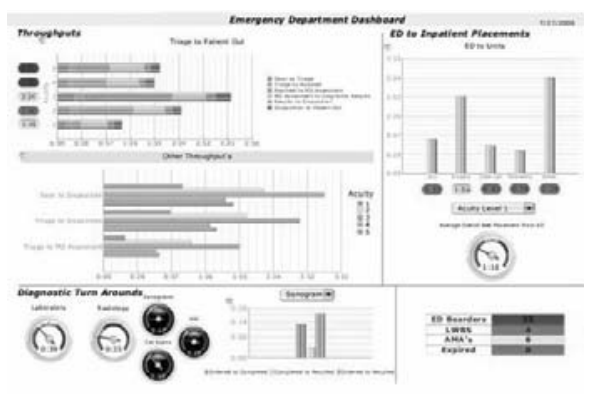

Fig. 2: Example of a complex ED dashboard.

\section{Health Service Performance Quali- ty Indicators}

$\mathrm{BI}$ dashboard tool is often regarded as a useful tool to monitor organization / department performance. The performance is measurable through key performance indicators (KPIs). KPIs are very important to management decision-making and are relied upon by all levels of an organization to measure success in achieving outcomes. The public health services need to identify its high-value high-risk data quality issues that support each KPI. However, in practice, this process is often conducted unsatisfactorily. For example, in public organizations, Theurer (1998) indicates that there are several "pitfalls" of performance measurement (and the use of KPIs) [17], closely related to the data quality management:

- Data by themselves have no meaning

- There is often lack of a strong commitment from leaders to move toward measuring performance and not just collecting data on effort

- Employees may not have the capacity to develop measures, so they use whatever 'measures' are already available

- If measurement focuses on negative accountability, managers and employees will seek to avoid accountability when things go wrong

In health services, the review of both national and international health quality indicators suggests that the most common KPIs dimensions for Health services are [13]:

- Effectiveness: the degree of achieving desirable outcomes, given the correct provision of evidence-based healthcare services to all who could benefit, but not to those who would not benefit;

- safety: the degree to which health care processes avoid, prevent, and ameliorate adverse outcomes or injuries that stem from the processes of health care itself;

- Responsiveness: how a system treats people to meet their legitimate non-health expectations (or often discussed as patientexperience);

- Accessibility: the ease with which health services are reached. Access can be physical, financial or psychological, and requires that health services are a priori available;

- Equity: defines the extent to which a system deals fairly with all concerned; and

- Efficiency: is the system's optimal use of available resources to yield maximum benefits or results.

These dimensions of KPIs will directly influence the data quality requirements in the ED processes and are considered in the design of this study.

\section{Data Quality}


Managers intuitively differentiate information from data, and describe information as data that has been processed. However, data and information are often used synonymously in practice, particularly when addressing quality issues. Therefore, this paper uses "data" interchangeably with "information", as well as using "data quality" (DQ) interchangeably with "information quality" (IQ).

The quality of data is multidimensional including accuracy, reliability, importance, consistency, precision, timeliness, fineness, understandability, conciseness, and usefulness [1[18][19]. It is also suggested that the quality of data is dependent on how the data will be used $[1][4][12][14][15][16]$. This fitness for use can be defined as the intersection of the quality dimension being considered, the use of data (purpose) and which data fields are used in order to fulfill the purpose [12].

When selecting appropriate data quality dimensions to investigate $\mathrm{ED}$ processes. This paper has adopted the four key dimensions that have been included in the Canadian Institution for
Health Information data quality framework (CIHI 2009). In the health domain this is likely to include the most important of all the dimensions of data quality, that of: accuracy, timeliness, comparability, and usability of clinical data. These dimensions of data quality, once defined need to be used consistently across units of health care and across time if comparisons and benchmarking are to be meaningful. The relevance dimension (the degree to which a database or registry meets the current and potential future needs of users) of the CIHI data quality framework is not fully considered as this study will not look into the actual database design of various ED systems, however, a recommendation has been made on how this can be included.

The above dimensions can be further decomposed into a number of elements. This will enable health institutions to adopt the definition that suits their data quality strategy most closely. With respects to the Canadian Institution for Health Information data quality framework and other data quality literature, the decomposed data quality dimensions for this study are in Table 2 .

\begin{tabular}{l|l|l}
\hline Dimensions & \multicolumn{1}{|c|}{ Decomposed } & \multicolumn{1}{c}{ Descriptions } \\
\hline Accuracy & Accuracy & The degree to which data are the correct values. \\
\cline { 2 - 3 } & Completeness & $\begin{array}{l}\text { The degree to which all data required by standards are cap- } \\
\text { tured; } \\
\text { The degree to which the documentation underlying the data } \\
\text { is complete. }\end{array}$ \\
\hline Timeliness & Freshness & $\begin{array}{l}\text { The difference between the end of the reference period and } \\
\text { when the data for that period is made available. }\end{array}$ \\
\cline { 2 - 3 } & Currency & $\begin{array}{l}\text { The difference between the end of the reference period and } \\
\text { when the data for that period is made available in a format } \\
\text { report. }\end{array}$ \\
\hline Comparabili- & Consistency & $\begin{array}{l}\text { The degree to which standards and definitions are compa- } \\
\text { rable over time. }\end{array}$ \\
\cline { 2 - 3 } & Integrity & $\begin{array}{l}\text { Changes are authorized and reasons are legitimate and rec- } \\
\text { orded }\end{array}$ \\
\hline Usability & Conformity & $\begin{array}{l}\text { Data entered as a result of correct interpretation of polices } \\
\text { and standards, thus meeting the analysis and reporting re- } \\
\text { quirements }\end{array}$ \\
\hline
\end{tabular}

Table 1: the decomposed data quality dimensions for this study. 


\section{Research Design}

This study tries to adopt a processoriented approach to understand how data quality issues emerged through the ED data collection process in order to provide a solid foundation for BI dashboard. Based on the literature, the following research model was developed to guide this study.

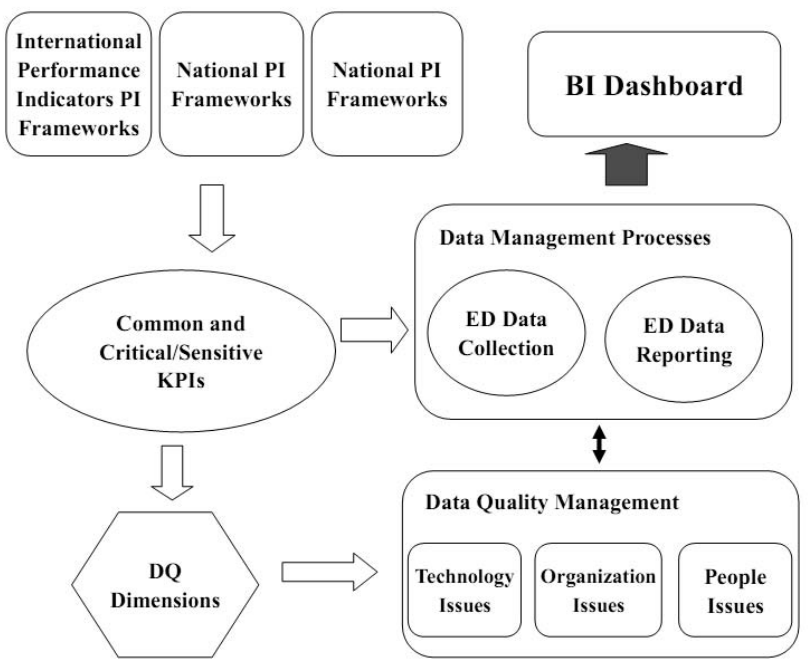

Fig. 3: Research Model (PI: Performance Indicator).

The data quality issues are categorized under the well-known TOP (Technology, Organization and People) framework. Mitroff and Linstone (1993) argue that any phenomenon, subsystem or system can be analyzed from what they call a Multiple Perspective method - employing different ways of seeing, to seek perspectives on the problem.

This study consists of two stages:

- Stage One: Primary data collection was conducted through observation in various ED departments, interviews with ED staff and non-ED staff who have roles of data stewards, data custodians, data users and data collectors in relation to the ED data management. Overall, more than 30 stakeholders were interviewed through individual or group face- to-face meetings and teleconferencing.

- Stage Two: The ED data collection and submission process flow charts were created. Data quality issues were summarized against the critical tasks within the processes and presented by using the TOP model.

\section{Findings}

The performance of Emergency Department is as a key performance indicator in the public health services. The waiting time in emergency department is often used for benchmarking purposes. The flow charts below provide the descriptions for major tasks of the ED visits and associated data quality issues. However, these tasks are not designed as a linear process. Thus, the process model is at- 
tached at the end to indicate the actual process.

\begin{tabular}{l|l|l}
\hline Perspectives & Issues & DQ Dimensions \\
\hline Technical & & \\
\hline Organizational & $\begin{array}{l}\text { The current policy does not take the actual waiting time } \\
\text { before triage into consideration. }\end{array}$ & $\begin{array}{l}\text { Completeness } \\
\text { Consistency }\end{array}$ \\
\hline
\end{tabular}

Table 2: Arrival in person - Data Quality Issues.

\begin{tabular}{l|l|l}
\hline Perspectives & Issues & DQ Dimensions \\
\hline Technical & $\begin{array}{l}\text { The ambulance information system is not linked to the } \\
\text { ED systems. }\end{array}$ & Consistency \\
\hline Organizational & $\begin{array}{l}\text { The current policy does not take the actual waiting time } \\
\text { before triage into consideration. }\end{array}$ & Completeness \\
& $\begin{array}{l}\text { There is an ambulance entry timestamp (when the am- } \\
\text { bulance staff clicks the button), but this data is not used } \\
\text { as the starting time for ED visits. }\end{array}$ & Consistency \\
\hline People & & \\
\hline
\end{tabular}

Table 3: Arrive in Ambulance - Data Quality Issues.

\begin{tabular}{|c|c|c|}
\hline Perspectives & Issues & DQ Dimensions \\
\hline Technical & & \\
\hline Organizational & $\begin{array}{l}\text { Due the lack of resources, the triage can take a long } \\
\text { time to complete. }\end{array}$ & Timeliness \\
\hline People & $\begin{array}{l}\text { The triage is conducted based on the triage staff's ex- } \\
\text { pertise, which may have mistakes. } \\
\text { The patient's situation may change over time (which } \\
\text { may require changes in the triage category). }\end{array}$ & $\begin{array}{l}\text { Accuracy } \\
\text { Timeliness } \\
\text { Integrity }\end{array}$ \\
\hline
\end{tabular}

Table 4: Triage - Data Quality Issues.

\begin{tabular}{|c|c|c|}
\hline Perspectives & Issues & DQ Dimensions \\
\hline Technical & $\begin{array}{l}\text { The current ED system user-interface is not well- } \\
\text { designed to neither embed the data verification rules } \\
\text { nor highlight critical data items. }\end{array}$ & $\begin{array}{l}\text { Accuracy } \\
\text { Completeness } \\
\text { Conformity }\end{array}$ \\
\hline Organizational & $\begin{array}{l}\text { The current process does not track those (patients) who } \\
\text { has submitted the form to be entered to the system, but } \\
\text { decided to leave the ED due to long waiting. }\end{array}$ & $\begin{array}{l}\text { Consistency } \\
\text { Completeness }\end{array}$ \\
\hline People & $\begin{array}{l}\text { The patient may never complete the form as they have } \\
\text { been called for the treatment. } \\
\text { The clerk may misread the patient's hand-writing and } \\
\text { not enter the correct data into the system. }\end{array}$ & $\begin{array}{l}\text { Accuracy } \\
\text { Completeness }\end{array}$ \\
\hline
\end{tabular}

Table 5: Initial registration - Data Quality Issues. 


\section{Data Collection Process}

\subsection{Arrival in Person}

The majority of patients arrives the hospital in person. It must be noted that some of these patients may not necessarily seek urgent assistance, but rather require simple clinical procedures due the inability to access these services from the general practicians.

The arrival time does not start from the moment that these patients enters the ED. Instead, it starts from the moment that he / she has been registered in the system by a triage nurse.

\subsection{Arrive in Ambulance}

A critical patient may arrive ED in ambulance. They will be transferred to an ambulance waiting area accompanied by ambulance staff. These patients will be seen by a triage nurse in the first instance.

\subsection{Triage}

Triage is officially considered as the start of ED visit. A triage nurse will ask for patient details and assign a triage category for the patient. This task usually takes $2 \sim 3$ minutes. The acquired data is entered into the system and a start time has been recorded. Once the triage is completed, the patient will be given a paper form to fill and asked to wait for the treatment.

It must be noted that in some instances, triage can take an average of 29 minutes in one state public hospital. Due the lack of resources, the patients cannot be seen and treated by a nurse or nurse practitioner (NP) or a doctor within the allowed time for the specific triage category that they have been assigned. Thus, instead of keeping the patient waiting, the triage nurse takes an effort to conduct an extensive examination of the patient which is beyond of the scope of his / her duties.

\subsection{Initial Registration}

Once the patient fills the form, they will submit the form to a data entry / admin clerk. The clerk will enter the patient information into the ED system.

It must note that the system may contain an incomplete record, which is difficult to differentiate from an incomplete record (the system hasn't recorded the patient departure time)

\subsection{Treatment}

The patient receives the treatment from nurses, NPs and doctors. Some emergency departments have allocated fast-track areas for simple procedures. During the treatment, nurses, NPS and doctors will record the procedures in the ED system (with or without the need of individual logins depending on the actual implement of ED systems).

\subsection{Admitted}

A proportion of patients will be admitted to the hospital. Once they have been physically transfer to the ward, the exit time is recorded as the end of ED visit. Their data will be transferred either manually or electronically to the Patient Admission System (PAS) systems.

\subsection{Discharge}

Some patients will be discharged from the hospital. A nurse, NP, doctor will record the departure time and discharge the patient. In some cases, admin clerks will check whether the patient data and departure time has been recorded properly.

If the patient arrives in ambulance, regardless whether he / she is admitted or discharged, the ambulance departure time is also recorded (the ambulance staff 
needs to click a button before leaving the hospital).

It is noted that there are inconsistency in recording the departure time in the system as it is not the exact moment that patient leaves the ED. The actual time can be when the ED staff has time to enter the data.

\section{Conclusion and Recommendation}

These analysis of data quality issues will not only serve as a roadmap of where to look for data quality problems but would also allow for possible rationalization and optimization of information resources to develop a meaningful and accurate BI dashboard in the ED environment.

\begin{tabular}{l|l|l}
\hline Perspectives & Issues & DQ Dimensions \\
\hline Technical & $\begin{array}{l}\text { When the ED and Patient Admission System (PAS) } \\
\text { systems are not developed by one vendor, the data in- } \\
\text { tegration issue occurs (often requires a manual } \\
\text { process). }\end{array}$ & $\begin{array}{l}\text { Integrity } \\
\text { Consistency } \\
\text { Accuracy }\end{array}$ \\
\hline Organizational & $\begin{array}{l}\text { Different area of services / hospital may use different } \\
\text { ED and PAS systems. }\end{array}$ & $\begin{array}{l}\text { Consistency } \\
\text { Conformity }\end{array}$ \\
\hline People & $\begin{array}{l}\text { The patient may not provide all required data. For ex- } \\
\text { ample, the insurance details were not carried. }\end{array}$ & $\begin{array}{l}\text { Accuracy } \\
\text { Timeliness } \\
\text { Integrity } \\
\text { Completeness }\end{array}$ \\
\hline
\end{tabular}

Table 6: Treatment - Data Quality Issues.

\begin{tabular}{l|l|l}
\hline Perspectives & Issues & DQ Dimensions \\
\hline Technical & $\begin{array}{l}\text { One implementation of ED systems does not have in- } \\
\text { dividual accounts for audit trails when a change has } \\
\text { been made. Changes can be made at any time. }\end{array}$ & $\begin{array}{l}\text { Integrity } \\
\text { Duplication }\end{array}$ \\
\hline Organizational & $\begin{array}{l}\text { The use of SNOMED CT system for clinical coding is } \\
\text { over-complicated in the ED environment. }\end{array}$ & $\begin{array}{l}\text { Accuracy } \\
\text { Consistency }\end{array}$ \\
\hline People & $\begin{array}{l}\text { It is not the first priority of individuals who updates } \\
\text { the system record especially the staff are busy in treat- } \\
\text { ing the patients. }\end{array}$ & $\begin{array}{l}\text { Accuracy } \\
\text { Timeliness } \\
\text { Integrity }\end{array}$ \\
\hline $\begin{array}{l}\text { There is a possibility for individuals to change the data } \\
\text { to meet the benchmark - e.g. assign a lower triage cat- } \\
\text { egory }\end{array}$ & $\begin{array}{l}\text { Accuracy } \\
\text { Integrity }\end{array}$ \\
\hline
\end{tabular}

Table 7: Admitted-Data Quality Issues.

\begin{tabular}{|c|c|c|}
\hline Perspectives & Issues & DQ Dimensions \\
\hline Technical & & \\
\hline Organizational & & \\
\hline People & $\begin{array}{l}\text { The departure time in the is not the exact moment that } \\
\text { patient leaves the ED. The actual exit time can be the } \\
\text { time when the ED staff has time to enter the data. }\end{array}$ & $\begin{array}{l}\text { Accuracy } \\
\text { Timeliness }\end{array}$ \\
\hline
\end{tabular}

Table 8: Discharge - Data Quality Issues. 
As much as possible, peoples' attitudes towards the care processes and particularly the IT systems which support these processes should also be recorded and analyzed as they would provide clues about possible 'workarounds' and also the motivations that may or may not drive them to have commitment to high levels of data quality. If for example staff express dissatisfaction with IT systems as cumbersome and unresponsive to their needs, it is likely to point to them not taking the requisite care in data entry for example or point to a practice of them maintaining their own locally based systems. Although such practices may be tolerated, proper governance of such data resources would be critical.

Organizational issues such as local culture for example must also be thoroughly examined to identify vulnerabilities such as duplication of data, contradictory classifications of data or differing interpretations of mandated or advisory departmental standards.

This study also indicates that understanding and mapping the clinical processes and associated 'data and information path' would be critical in establishing the points for assessing the data quality along the various business processes. With this understanding, the BI developers together with the business process owners (e.g. doctors) will be able to define performance standards for key operational processes, and the BI system will monitor events, analyze patterns, and help users determine what actions to take in a reliable way.

\section{References}

[1] Ballou, D.P. \& Pazer, H.L. (1995) Designing Information Systems to Optimize the Accuracy-timeliness Tradeoff. Information Systems Research. 6(1), 51-72
[2] Bazarian JJ, Schneider SM et al. Do admitted patients held in the emergency department impair throughput of treat and release patients? Acad Emerg Med. 1996; 3(12): 1113-1118.

[3] Canadian Institute for Health Information (CIHI), (2005), The CIHI Data Quality Framework 2009, URL: http://www.cihi.ca/cihiweb/en/downl oads/data_quality_framework_2009 e.pdf, online accessed [1/6/2010]

[4] English, L.P., (1999) Improving Data Warehouse and Business Information Quality: Methods for reducing costs and increasing Profits, Willey \& Sons

[5] Gendron S. M. and D'Onofrio, J. M. (2001), Data Quality in the Healthcare Industry, Data Quality, 7:1

[6] Graff L, Stevens C, et al. Measuring and Improving Quality in Emergency Medicine. Acad Emerg Med. 2002; 9 (11): 1091-1107.

[7] Holland L, Smith L et al., (2005) Reducing Laboratory Turnaround Time Outliers Can Reduce Emergency Department Patient Length of Stay. Am J Clin Pathol. 2005; 125(5) 672-674.

[8] Lewandrowski K. (2004), How the clinical laboratory and the emergency department can work together to move patients through quickly. Clinical Leadership Management Review, 2004; 18(3): 155-9.

[9] Lindsay P, Schull M, et al. (2002), The Development of Indicators to Measure the Quality of Clinical Care in EDs Following the ModifiedDelphi Approach. Academic Emergency Medicine, 2002; 9(11): 11311139.

[10] McKee, M. (2001): Measuring the efficiency of health systems. British Medical Journal, 323(7308): 295296.

[11] Mitroff, I. I. and H. A. Linstone, (1993), The Unbounded Mind: Breaking the Chains of Traditional Busi- 
ness Thinking, New York, OxFord University Press, 1993.

[12] Neely, M.P. (2001) A Proposed Framework for the Analysis of Source Data in a Data Warehouse, Proceedings of the Sixth International Conference on Information Quality, November 2001, Cambridge, MA, USA, MIT

[13] OECD, (2006), "Health Care Quality Indicators Project Conceptual Framework Paper", Editors: Edward Kelley and Jeremy Hurst, OECD Health Working Paper, DELSA/HEA/WD/HWP(2006)3

[14] Orr, K. (1998) Data Quality and System Theory. Communications of the ACM. 41(2), 66-71

[15] Salaun, Y., and Flores, K., (2001), "Information Quality: Meeting the Needs of the Consumer", In- ternational Journal of Information Management, 21(1), 2001, pp. 21-37.

[16] Strong, D.M. (1997) IT Process designs for Improving Information Quality and reducing Exception Handling: A Simulation Experiment. Information and Management. 31, 251263

[17] Theurer, J., (1998), Seven pitfalls to avoid when establishing performance measures. Public Management, 1998. 80(7): p. 21-24.

[18] Wand, Y. \& Wang, R.Y. (1996) Anchoring Data Quality Dimensions in Ontological Foundations. Communications of the ACM. 39(11), 86-95

[19] Wang, R.Y., and Strong, D.M., (1996) "Beyond Accuracy: What Data Quality Means to Data Consumers", Journal of Management Information Systems, 12(4), 1996, pp. 5-33. 